\title{
Enhancement of dairy sheep cheese eating quality with increased n-3 long-chain polyunsaturated fatty acids
}

\author{
Quang Vu Nguyen, ${ }^{1,2}$ Hung Van Le, ${ }^{1,3}$ Don Viet Nguyen, ${ }^{1,3}$ Bunmi S. Malau-Aduli, ${ }^{4}$ Peter D. Nichols, ${ }^{1,5}$ \\ and Aduli E. O. Malau-Aduli ${ }^{1 *}$ \\ ${ }^{1}$ Animal Genetics and Nutrition, Veterinary Sciences Discipline, College of Public Health, Medical and Veterinary Sciences, \\ Division of Tropical Health and Medicine, James Cook University, Townsville, Queensland 4811, Australia \\ ${ }^{2}$ College of Economics and Techniques, Thai Nguyen University, Thai Nguyen 24122, Vietnam \\ ${ }^{3}$ Institute of Animal Science, Thuy Phuong, Bac Tu Liem, Hanoi 129909, Vietnam \\ ${ }^{4}$ College of Medicine and Dentistry, Division of Tropical Health and Medicine, James Cook University, Townsville, Queensland 4811, Australia \\ ${ }^{5}$ CSIRO Oceans and Atmosphere, Hobart, Tasmania 7001, Australia
}

\section{ABSTRACT}

This study investigated the effect of different plant oil-infused and rumen-protected wheat-based pellets containing eicosapentaenoic acid (EPA, 20:5n-3) and docosahexaenoic acid (DHA, 22:6n-3) on n-3 long-chain $\left(\geq \mathrm{C}_{20}\right)$ polyunsaturated fatty acid (LC-PUFA) content, fatty acid recovery, and sensory attributes of ripened cheese from dairy sheep. During a 10-wk supplementary feeding trial, 60 dairy ewes balanced by live weight, milk yield, parity, and sire breed were randomly divided into 6 groups that were (1) supplemented with on-farm existing commercial wheat-based pellets without oil inclusion (control) or supplemented with wheat-based pellets infused with $50 \mathrm{~mL} / \mathrm{kg}$ dry matter of oils from (2) canola, (3) rice bran, (4) flaxseed, (5) safflower, and (6) rumen-protected EPA + DHA. Milk samples from each treatment were collected separately by sire breed during the experimental period for cheese processing at the end of the experiment. Twelve batches of cheese (2 batches per treatment) were processed and ripened for $120 \mathrm{~d}$. Three cheese samples were collected and analyzed for each cheese making session (total of 36 cheese samples) at d 120 of ripening. Processed cheese of rumen-protected EPA + DHA had the most efficiency at elevating total n-3 LC-PUFA [total EPA + DHA + docosapentaenoic acid (DPA, 22:5n-3] content compared with the control (0.49 vs. $0.28 \%$ ). Flaxseed elicited the greatest enhancement of $\alpha$-linolenic acid (ALA, 18:3n-3), whereas safflower was the most effective diet in enhancing the level of linoleic acid (18:2n-6) in cheese ( 1.29 vs. $0.71 \%$ and 4.8 vs. $3.3 \%$, respectively). Parallel recoveries of n-3 and n-6 LC-PUFA were

Received June 15, 2018.

Accepted September 13, 2018.

*Corresponding author: aduli.malauaduli@jcu.edu.au observed across all treatments except for $\alpha$-linolenic acid and EPA. Cheese eating sensory traits were also highly affected by oil supplementation, with the highest score of 7.5 in cheese from the rice bran and flaxseed treatments. These results provide new insights into the biological mechanisms and processes that determine dairy ewe milk productivity by underpinning the vital biological role of n-3 LC-PUFA in not only enhancing the healthy composition of cheese from ewes but also translating it into consumer acceptability.

Key words: sheep cheese, n-3 long-chain polyunsaturated fatty acid, sensory eating quality, food functionality, oil

\section{INTRODUCTION}

Over the last 3 decades, numerous studies have examined the health benefits of $n-3$ long-chain $\left(\geq C_{20}\right)$ PUFA (LC-PUFA) and consistently demonstrated their vital role in inhibiting chronic diseases. According to the global status report on noncommunicable diseases of the World Health Organization (Mendis and Chestnov, 2014), 38 million people died of chronic diseases and unhealthy dietary habits, with the deficiency of n-3 LC-PUFA intake as one of the main causes of death. In response to this health concern, a large number of studies aimed at increasing n-3 LC-PUFA content in human foods have emerged. Cheese is the most popular long-shelf-life dairy product, and its global production was predicted to increase by $19 \%$ between 2008 and 2020 (OECD/FAO, 2011). Among the numerous cheese varieties, sheep cheese has been reported to have higher levels of beneficial PUFA than cow and goat cheeses under the same processing conditions (Prandini et al., 2011). Therefore, the enhancement of health-beneficial fatty acids (FA) in sheep cheese has been of immense research interest (Zhang et al., 2006a,b; Bodas et al., 2010; Buccioni et al., 2012). 
The FA profile of cheese, especially beneficial FA that have positive effects on human health, primarily depends on the FA composition of raw milk rather than cheese processing technology (Collomb et al., 2006; Bisig et al., 2007; Prandini et al., 2011). Because dietary FA contribute all of the long-chain FA in milk fat (Chilliard et al., 2007), dietary supplementation of ruminants with UFA remains one of the most popular ways to alter milk fat profile (Reynolds et al., 2006; Zhang et al., 2006a,b; Castro et al., 2009; Gomez-Cortes et al., 2011) and increase the proportion of PUFA in sheep milk and cheese. However, recent research has focused only on limited sources of unsaturated plant lipids, mostly linseed, soybean, safflower, and sunflower (Nudda et al., 2014). This suggests the need for further investigation into the effect of other available plant oil sources, including canola and rice bran, on FA composition of dairy sheep products. Furthermore, about 30\% of milk processed in Australia is used for the production of cheese (Dairy Australia, 2016). However, to the best of our knowledge, the available published literature about the concentration of beneficial FA, including n-3 LCPUFA, in cheese under Australian on-farm production conditions is at best scant or nonexistent, thus representing a major knowledge gap that this study intends to fill. Therefore, the objective of this study was to determine the effects of supplementing grazing Australian dairy ewes with oil-infused canola, rice bran, flaxseed, safflower, and rumen-protected eicosapentaenoic acid and docosahexaenoic acid pellets on the concentrations and recovery of LC-PUFA as well as the eating quality of sheep cheese. It was hypothesized that supplementing grazing dairy ewes with different sources of dietary oils, including those containing n-3 and n-6 PUFA, will affect the concentration and recovery of n-3 LC-PUFA and alter the appearance, texture, taste, flavor, and aroma of ripened cheese.

\section{MATERIALS AND METHODS}

\section{Animals and Treatments}

This study was carried out at Grandvewe Cheeses Farm, Birchs Bay, Woodbridge, Tasmania, Australia. All experimental protocols were approved by the University of Tasmania Animal Ethics Committee in accordance with the 1993 Tasmanian Animal Welfare Act and the 2004 Australian Code of Practice for the Care and Use of Animals for Scientific Purposes (animal ethics permit number A0015657).

Sixty lactating Awassi and Awassi $\times$ East Friesian crossbred ewes in mid lactation were randomly assigned to 6 groups balanced by breed, parity $(2.8 \pm$
$0.5)$, live weight $(59 \pm 5.9 \mathrm{~kg})$, and milk yield $(657 \pm$ $100 \mathrm{~g} / \mathrm{d}$ ). The 6 groups were (1) supplemented with onfarm existing commercial wheat-based pellets without oil inclusion (control) or supplemented with wheatbased pellets infused with $50 \mathrm{~mL} / \mathrm{kg}$ DM of oils from (2) canola (CO), (3) rice bran (RBO), (4) flaxseed (FSO), (5) safflower (SFO), and (6) rumen-protected eicosapentaenoic acid (EPA) + docosahexaenoic acid (DHA; treatment referred to as RPO). All supplementary diets were isocaloric and isonitrogenous. The nutritional composition of the experimental diets is shown in Table 1. Ewes were grazed as a single mob in the same paddock with free access to local natural velvet tussock grass, hay, and fresh water. Each ewe received 1 $\mathrm{kg}$ of the pellet supplements daily during milking time at $0600 \mathrm{~h}$ for $10 \mathrm{wk}$, including an initial 2-wk adjustment period followed by an 8-wk experimental period. The proportions of experimental diets $\mathrm{CO}, \mathrm{RBO}, \mathrm{FSO}$, SFO, and RPO were gradually increased by $100 \mathrm{~g} / \mathrm{d}$ during the transition period until the attainment of 1 $\mathrm{kg} / \mathrm{d}$ per head on d 10. Milk in each group was collected separately by sire breed during the experimental period using the DeLaval sheep milking platform (DeLaval, Tumba, Sweden) and stored at the farm in sanitized plastic containers at $-20^{\circ} \mathrm{C}$ for cheese processing at the end of the experiment.

\section{Cheese Making}

Twelve batches were processed following Grandvewe Cheeses farm standard protocols without pasteurization. Briefly, raw milk was heated to $38^{\circ} \mathrm{C}$ in a cheese vat and rennet was added to form curd. The curds were then cut, stirred into very small pieces, and left to compact at the bottom of the vat. Then, the curd was removed from the vat and the whey was drained and put into small, 1-kg plastic mold blocks. After brine salting for $24 \mathrm{~h}$, the cheeses were transferred to a ripening room adjusted to remain at constant temperature $\left(11-12^{\circ} \mathrm{C}\right)$ and 75 to $80 \%$ relative humidity for $120 \mathrm{~d}$. Three cheeses were randomly collected and stored in air-tight bags at $-20^{\circ} \mathrm{C}$ until each batch was analyzed at d 120 (36 cheese samples in total), when they were ripened and ready for trading.

\section{Chemical Analysis of Experimental Feeds}

Samples of supplementary and basal diets were collected weekly and stored at $-20^{\circ} \mathrm{C}$ during the feeding trial, dried at a constant temperature of $65^{\circ} \mathrm{C}$ in a fan-forced oven before being ground to pass through a 1-mm screen using a Thomas model 4 laboratory mill (Thomas Scientific, Swedesboro, NJ), and then used 
Table 1. Proximate analysis of pasture, hay, and the experimental diets

\begin{tabular}{|c|c|c|c|c|c|c|c|c|}
\hline \multirow{2}{*}{$\begin{array}{l}\text { Component } \\
\text { (\% of DM) }\end{array}$} & \multirow[b]{2}{*}{ Pasture } & \multirow[b]{2}{*}{ Hay } & \multicolumn{6}{|c|}{ Diet $^{1}$} \\
\hline & & & Control & $\mathrm{CO}$ & $\mathrm{RBO}$ & FSO & $\mathrm{SFO}$ & $\mathrm{RPO}$ \\
\hline DM & 96.5 & 95.5 & 91.5 & 93.0 & 91.6 & 90.0 & 91.7 & 91.6 \\
\hline $\mathrm{OM}$ & 90.5 & 97.3 & 92.2 & 93.3 & 92.7 & 91.0 & 91.8 & 92.0 \\
\hline Ash & 9.5 & 2.7 & 7.8 & 6.7 & 7.3 & 9.0 & 8.2 & 8.0 \\
\hline $\mathrm{ADF}$ & 45.5 & 37.6 & 10.6 & 7.1 & 8.1 & 9.7 & 9.0 & 8.5 \\
\hline NDF & 69.9 & 68.3 & 30.0 & 21.8 & 19.4 & 23.3 & 23.9 & 22.0 \\
\hline Ether extract & 1.4 & 1.2 & 3.3 & 5.7 & 5.2 & 5.4 & 5.0 & 5.1 \\
\hline $\mathrm{CP}$ & 4.7 & 4.3 & 14.6 & 14.0 & 14.7 & 14.6 & 14.5 & 15.6 \\
\hline TDN & 48.5 & 54.1 & 73.4 & 75.9 & 75.2 & 74.1 & 74.5 & 74.9 \\
\hline $\mathrm{ME}(\mathrm{MJ} / \mathrm{kg}$ of $\mathrm{DM})$ & 7.1 & 8.1 & 11.7 & 12.2 & 12.0 & 11.8 & 11.9 & 12.0 \\
\hline
\end{tabular}

${ }^{1} \mathrm{CO}=$ canola oil; $\mathrm{RBO}=$ rice bran oil; $\mathrm{FSO}=$ flaxseed oil; $\mathrm{SFO}=$ safflower oil; $\mathrm{RPO}=$ rumen-protected oil.

for analyzing DM and ash contents according to AOAC International (1999). An Ankom220 fiber analyzer was used to analyze NDF and ADF, and ether extract was measured using an AnkomXT15 fat/oil extractor (Ankom Technology, Macedon, NY). The CP percentage was calculated based on the value of nitrogen that was determined using a Thermo Finnigan EA 1112 Series flash elemental analyzer (Thermo Scientific, Waltham, MA). The chemical compositions of the control, treatments, pasture, and hay are presented in Table 1.

\section{FA Analysis}

Approximately $5 \mathrm{mg}$ of diet samples and $0.5 \mathrm{~g}$ of raw milk samples were accurately weighed into methylation tubes and freeze dried to remove moisture according to Otto et al. (2014), and $0.1 \mathrm{~g}$ of unground cheese sample was extracted for total lipids according to the procedures reported by Malau-Aduli et al. (2016). The dried feed samples and aliquots of the extracted lipids from cheese samples were then methylated in a solution of methanol $/ \mathrm{HCl} /$ dichloromethane $\left(10 / 1 / 1 ; 3 \mathrm{~mL} ; 80^{\circ} \mathrm{C}\right.$ for $2 \mathrm{~h}$ ) to produce FAME, which were extracted (hexane/dichloromethane, $4 / 1 ; 2 \mathrm{~mL}, 3 \times$ ) and transferred to glass GC vials. The FAME were diluted with dichloromethane containing C19:0 FAME as the internal injection standard before analyses were performed using an Agilent Technologies (Santa Clara, CA) 7890B gas chromatograph equipped with an Equity-1 fused silica capillary column $(15 \mathrm{~m} \times 0.1-\mathrm{mm}$ i.d. and $0.1-\mu \mathrm{m}$ film thickness), a flame ionization detector, a split/splitless injector, and an Agilent Technologies 7683B Series autosampler. Oven temperature profile was set initially at $120^{\circ} \mathrm{C}$ for 1 min and was raised to $270^{\circ} \mathrm{C}$ at $10^{\circ} \mathrm{C} /$ min, then to $310^{\circ} \mathrm{C}$ at $5^{\circ} \mathrm{C} / \mathrm{min}$. ChemStation software (Agilent Technologies) was used to quantify peak areas. We performed GC-MS analyses on selected samples to confirm FA identities using a Thermo Scientific 1310 GC coupled with a TSQ triple quadrupole. Samples were injected using a Tripleplus RSH autosampler with a nonpolar HP-5 Ultra 2 bonded-phase column (50 $\mathrm{m} \times 0.32-\mathrm{mm}$ i.d. $\times 0.17-\mu \mathrm{m}$ film thickness; Agilent Technologies). The HP-5 column was of similar polarity to the column used for GC analyses. The initial oven temperature of $45^{\circ} \mathrm{C}$ was held for $1 \mathrm{~min}$, followed by temperature programming at $30^{\circ} \mathrm{C} / \mathrm{min}$ to $140^{\circ} \mathrm{C}$, then at $3^{\circ} \mathrm{C} / \mathrm{min}$ to $310^{\circ} \mathrm{C}$, where it was held for $12 \mathrm{~min}$. Helium was used as the carrier gas. Mass spectrometer operating conditions were as follows: electron impact energy $=70 \mathrm{eV}$; emission current $=250 \mu \mathrm{A}$; transfer line $=310^{\circ} \mathrm{C} ;$ source temperature $=240^{\circ} \mathrm{C} ;$ scan rate $=$ $0.8 \mathrm{scan} / \mathrm{s}$; mass range $=40$ to 650 Da. Mass spectra were acquired and processed with Thermo Scientific Xcalibur software.

\section{Calculation of Cheese FA Recovery}

Recovery of cheese for selected individual FA $\left[\mathrm{REC}_{(\mathrm{FA})}\right]$ was calculated using the formula described by Cattani et al. (2014):

$$
\operatorname{REC}_{(\mathrm{FA})}=\frac{\text { cheese fatty } \operatorname{acid}(\mathrm{g})}{\text { milk fatty } \operatorname{acid}(\mathrm{g})} \times \frac{\text { cheese fat }(\mathrm{g})}{\text { milk fat }(\mathrm{g})} .
$$

\section{Consumer Sensory Evaluation}

Following the procedure of Fuentes et al. (2015), a sensory evaluation test was conducted at the University of Tasmania by trained consumer panelists comprising 25 male and female volunteer staff and students (aged between 20 and $55 \mathrm{yr}$ ) who habitually consume cheese in their diets. The assessors had a training session before the official testing so that they were familiar with the whole process of hedonic evaluation of sensory characteristics. As demonstrated by Lim (2011), the 9-point hedonic scale is easy, simple, reliable, and highly effective for quantifying sensory differences 
among foods and for predicting consumer acceptability; hence, it was chosen in this study. In both sessions, cheese was refrigerated until served as $1.5-\mathrm{cm}^{3}$ cubes in a completely randomized block design in a tasting room at $20^{\circ} \mathrm{C}$. Panelists were given the opportunity to taste each sample 5 times, including 2 of the cheeses for pretesting sessions (Mughetti et al., 2012). Unsalted crackers and water were used to remove any lingering effects of the previous samples. A 9-point hedonic scale was used to rate the degree of liking, appearance, aroma, flavor, texture, and overall acceptability, where $1=$ dislike extremely, $2=$ dislike very much, $3=$ dislike moderately, $4=$ dislike slightly, $5=$ neither like nor dislike, $6=$ like slightly, $7=$ like moderately, $8=$ like very much, and $9=$ like extremely.

\section{Statistical Analysis}

Statistical analysis of all collected data was performed in SAS version 9.2 (SAS Institute, Cary, NC). Initially, means, standard deviations, standard errors, and minimum and maximum values of data were computed using PROC MEANS, and these were scrutinized for any data entry errors. Selected cheese FA were subjected to a general linear model (PROC GLM) mixed model analysis with treatment, breed, and their second-order interactions fitted as fixed effects, and milk yield and ewe age were fitted as random effects. All nonsignificant interactions were removed from the final analytical model. Level of significance threshold was set at $P$ $<0.05$, and differences between means were established using Tukey's probability pairwise comparison test.

\section{RESULTS}

\section{FA Composition and Recovery of the Main n-6 and n-3 LC-PUFA in Ripened Cheese}

As depicted in Table 2, there were differences in FA percentages between the diets. These differences resulted in significant variations in selected raw milk FA (Table 3) and cheese FA (Table 4). The largest improvement in the proportion of total n-3 PUFA was recorded in cheese produced from milk from ewes fed FSO and RPO $(P<0.001 ; 161$ and $158 \%$, respectively $)$ compared with the control (unsupplemented) group. The enrichment of total n-3 PUFA in cheese produced from animals in the FSO group was mainly attributable to the significant increase in the proportion of $\alpha$-linolenic acid (ALA, 18:3n-3; 1.30\%) compared with the control $(0.71 \%)$. In contrast, the significant enrichment of total n-3 PUFA observed in cheese produced from animals in the RPO treatment compared with the control group was attributable to increases in the proportions of ALA (1.02 vs $0.71 \%)$ as well as total n-3 LC-PUFA [EPA + DHA + docosapentaenoic acid (DPA); 0.50 vs. $0.29 \%$; $P<0.001$; Table 4]. In terms of linoleic acid (LA), the greatest percentage was observed in the cheese produced from the SFO group, which increased by $147 \%$ compared with the control group (4.78 vs $3.26 \%$ ) and followed by FSO (3.79\%), RPO (3.52\%), RBO (3.45\%), and $\mathrm{CO}(3.06 \% ; P<0.001)$.

The effect of oil supplements on the recovery of main n-6 and n-3 LC-PUFA is depicted in Table 5. In terms of individual FA, there were significant differences in

Table 2. Selected fatty acid composition (\% of total fatty acids) of pasture, hay, and experimental diets

\begin{tabular}{|c|c|c|c|c|c|c|c|c|}
\hline \multirow[b]{2}{*}{ Fatty acid ${ }^{1}$} & \multirow[b]{2}{*}{ Pasture } & \multirow[b]{2}{*}{ Hay } & \multicolumn{6}{|c|}{ Diet $^{2}$} \\
\hline & & & Control & $\mathrm{CO}$ & $\mathrm{RBO}$ & FSO & $\mathrm{SFO}$ & $\mathrm{RPO}$ \\
\hline $14: 0$ & 1.60 & 2.85 & 0.05 & 0.14 & 0.14 & 0.14 & 0.22 & 2.35 \\
\hline $16: 0$ & 18.8 & 35.8 & 21.8 & 12.4 & 17.4 & 11.0 & 14.0 & 19.5 \\
\hline $18: 0$ & 4.48 & 7.57 & 1.05 & 1.12 & 2.28 & 3.38 & 2.26 & 2.86 \\
\hline $16: 1 \mathrm{n}-7 \mathrm{cis}$ & 0.65 & 0.55 & 0.13 & 0.27 & 0.20 & 0.25 & 0.22 & 4.03 \\
\hline $18: 1 \mathrm{n}-9$ cis & 10.2 & 0.0 & 20.5 & 41.8 & 31.8 & 18.8 & 20.3 & 20.9 \\
\hline $18: 1 \mathrm{n}-7 \mathrm{cis}$ & 1.31 & 1.15 & 1.22 & 2.54 & 1.11 & 1.83 & 1.48 & 1.90 \\
\hline $18: 2 n-6$ LA & 18.7 & 8.6 & 47.0 & 33.8 & 41.1 & 40.9 & 56.5 & 35.7 \\
\hline $18: 3 n-3$ ALA & 24.1 & 12.2 & 3.0 & 4.8 & 2.3 & 20.5 & 1.7 & 2.7 \\
\hline 20:5n-3 EPA & 0.00 & 0.00 & 0.00 & 0.13 & 0.10 & 0.12 & 0.07 & 2.50 \\
\hline 22:6n-3 DHA & 0.00 & 0.00 & 0.00 & 0.00 & 0.00 & 0.00 & 0.00 & 1.63 \\
\hline 22:5n-3 DPA & 0.00 & 0.00 & 0.00 & 0.00 & 0.00 & 0.00 & 0.00 & 0.54 \\
\hline$\Sigma \mathrm{SFA}$ & 41.2 & 69.1 & 25.3 & 15.3 & 22.0 & 16.0 & 18.0 & 27.1 \\
\hline$\Sigma M U F A$ & 15.0 & 7.1 & 23.4 & 45.7 & 34.0 & 21.7 & 22.9 & 28.3 \\
\hline$\Sigma P U F A$ & 43.8 & 23.8 & 51.3 & 39.0 & 44.0 & 62.3 & 59.1 & 44.6 \\
\hline इn-6 PUFA & 19.5 & 10.7 & 47.8 & 34.0 & 41.4 & 41.6 & 57.0 & 37.1 \\
\hline इn-3 PUFA & 24.2 & 12.3 & 3.1 & 4.9 & 2.4 & 20.6 & 1.7 & 7.4 \\
\hline$\Sigma \mathrm{EPA}+\mathrm{DHA}+\mathrm{DPA}$ & 0.00 & 0.00 & 0.00 & 0.13 & 0.10 & 0.12 & 0.07 & 4.67 \\
\hline
\end{tabular}

${ }^{1} \mathrm{LA}=$ linoleic acid; ALA $=\alpha$-linolenic acid; EPA = eicosapentaenoic acid; DHA = docosahexaenoic acid; DPA = docosapentaenoic acid. ${ }^{2} \mathrm{CO}=$ canola oil; $\mathrm{RBO}=$ rice bran oil; $\mathrm{FSO}=$ flaxseed oil; $\mathrm{SFO}=$ safflower oil; $\mathrm{RPO}=$ rumen-protected oil. 
Table 3. Selected fatty acid composition (\% of total fatty acids) of raw milk from ewes fed the experimental diets

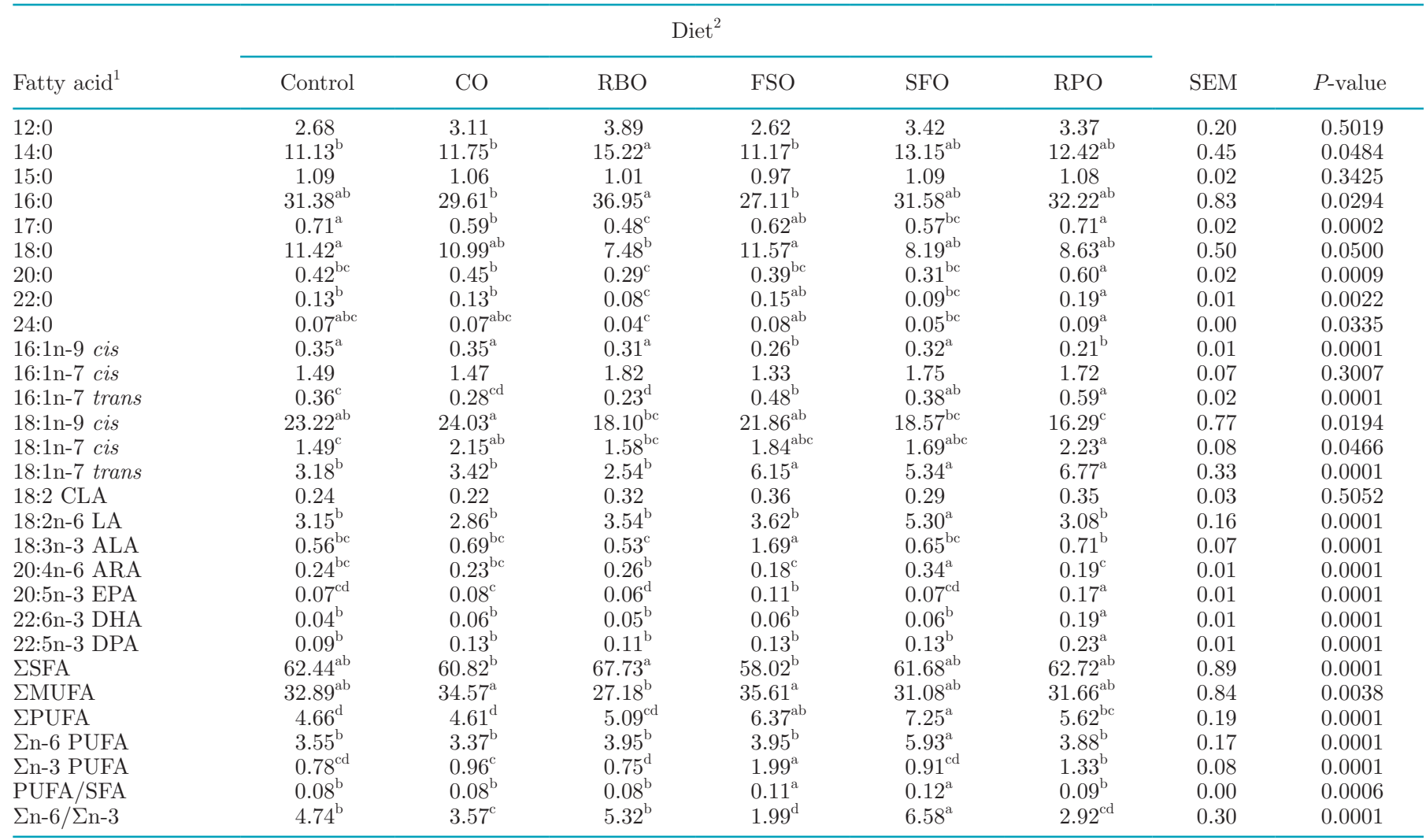

${ }^{\mathrm{a}-\mathrm{d}}$ Means within a row with different superscripts within a fixed factor significantly differ $(P<0.05)$.

${ }^{1} \mathrm{LA}=$ linoleic acid; ALA $=\alpha$-linolenic acid; ARA $=$ arachidonic acid; EPA $=$ eicosapentaenoic acid; DHA $=$ docosahexaenoic acid; DPA $=$ docosapentaenoic acid.

${ }^{2} \mathrm{CO}=$ canola oil $\mathrm{RBO}=$ rice bran oil; $\mathrm{FSO}=$ flaxseed oil; $\mathrm{SFO}=$ safflower oil; $\mathrm{RPO}=$ rumen-protected oil.

ALA $(P<0.0090)$ and EPA $(P<0.0098)$ recoveries due to dietary supplementation, with the highest transferred rates of ALA and EPA observed in RPO (1.09) and SFO (1.03). The recoveries of group FA had similar patterns across treatments except for n-3 PUFA $(P<$ $0.0514)$, which ranged from a minimum of 0.56 in FSO to a maximum of 0.86 in RPO.

\section{Concentration of the Main n-6 and n-3 LC-PUFA per Standard Serving of Cheese and Cheese Sensory Test}

To investigate the potential nutritional benefits to consumers, LA and the main n-3 LC-PUFA of cheese were also analyzed in quantitative terms per serving (mg/40 g; Table 6). In relation to the proportion of FA (expressed as \% of total FA), cheese in the FSO treatment had the greatest amount of ALA (113.8 mg/40 g), and RPO and SFO had the highest total n-3 LC-PUFA $(44.3 \mathrm{mg} / 40 \mathrm{~g})$ and LA (414.3 mg/40 g), respectively.
Despite the application of the same cheese making process to all treatments, the varied preferences of cheese tasting panelists across treatments reflect the effect of dietary supplements on eating quality of the final product. Cheeses made from RBO and FSO milk yielded the highest scores for all sensory traits, with an overall acceptability or overall liking of 7.5, implying that the consumers' preferences for these cheeses were between "like moderately" and "like very much." In contrast, the $\mathrm{CO}$ cheese had a slightly negative effect on sensory attributes, with the lowest overall liking rating from the panelists at 4.4 (slightly dislike) compared with 5.7 (neither like nor dislike) in the control (Table 7). Inclusion of RPO and SFO in the diets elicited similar levels of all tested sensory attributes except for the improvement in appearance at 6.1 and 6.2 , respectively. As shown in Table 8, there were strong positive correlations between all sensory traits, in which flavor was the key assessed attribute contributing to the consumer enjoyment of sheep cheese $(\mathrm{r}=0.91 ; P<0.001)$. Partial 
Table 4. Selected fatty acid composition (\% of total fatty acids) of ripened cheese from milk from ewes fed the experimental diets

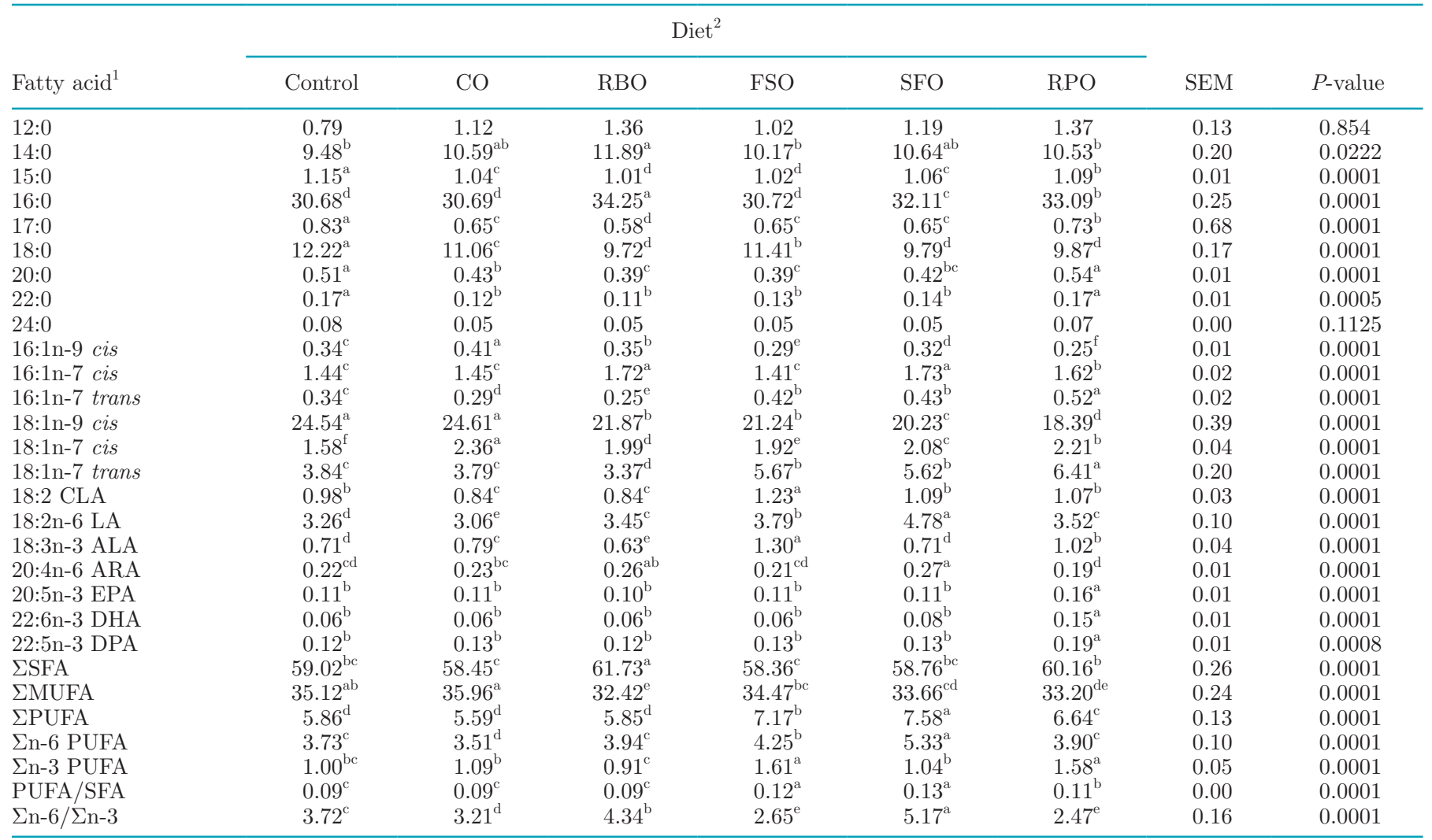

${ }^{\mathrm{a}-\mathrm{f}}$ Means within a row with different superscripts within a fixed factor significantly differ $(P<0.05)$.

${ }^{1} \mathrm{LA}=$ linoleic acid; ALA $=\alpha$-linolenic acid; ARA $=$ arachidonic acid; EPA $=$ eicosapentaenoic acid; DHA $=$ docosahexaenoic acid; DPA $=$ docosapentaenoic acid.

${ }^{2} \mathrm{CO}=$ canola oil RBO $=$ rice bran oil $; \mathrm{FSO}=$ flaxseed oil; $\mathrm{SFO}=$ safflower oil; $\mathrm{RPO}=$ rumen-protected oil.

sums of SFA and PUFA were correlated positively with eating quality traits, ranging from weak to moderate, whereas correlations were strongly negative $(\mathrm{r}=-0.58$ to 0.76) for the sum of MUFA. However, correlations between selected individual and partial sums of FA were not statically significant (Table 8).

Table 5. Recovery of n-3 and n-6 PUFA in ripened cheese from milk from ewes fed the experimental diets

\begin{tabular}{|c|c|c|c|c|c|c|c|c|}
\hline \multirow[b]{2}{*}{ Fatty acid ${ }^{1}$} & \multicolumn{6}{|c|}{$\operatorname{Diet}^{2}$} & \multirow[b]{2}{*}{ SEM } & \multirow[b]{2}{*}{$P$-value } \\
\hline & Control & $\mathrm{CO}$ & $\mathrm{RBO}$ & FSO & $\mathrm{SFO}$ & $\mathrm{RPO}$ & & \\
\hline $18: 2 \mathrm{n}-6 \mathrm{LA}$ & 0.66 & 0.67 & 0.64 & 0.73 & 0.63 & 0.83 & 0.02 & 0.1045 \\
\hline $18: 3 n-3$ ALA & $0.84^{\mathrm{ab}}$ & $0.73^{\mathrm{bc}}$ & $0.78^{\mathrm{bc}}$ & $0.54^{\mathrm{c}}$ & $0.75^{\mathrm{bc}}$ & $1.09^{\mathrm{a}}$ & 0.04 & 0.0090 \\
\hline $20: 5 n-3$ EPA & $0.97^{\mathrm{ab}}$ & $0.83^{\mathrm{abc}}$ & $1.02^{\mathrm{a}}$ & $0.76^{\mathrm{bc}}$ & $1.03^{\mathrm{a}}$ & $0.68^{\mathrm{c}}$ & 0.03 & 0.0098 \\
\hline 22:6n-3 DHA & 0.89 & 0.64 & 0.87 & 0.74 & 0.95 & 0.52 & 0.05 & 0.1347 \\
\hline 22:5n-3 DPA & 0.77 & 0.70 & 0.73 & 0.70 & 0.68 & 0.59 & 0.03 & 0.8512 \\
\hline$\Sigma \mathrm{EPA}+\mathrm{DHA}+\mathrm{DPA}$ & 0.87 & 0.72 & 0.84 & 0.72 & 0.83 & 0.59 & 0.03 & 0.1745 \\
\hline$\Sigma \mathrm{SFA}$ & 0.59 & 0.61 & 0.59 & 0.69 & 0.64 & 0.68 & 0.01 & 0.2070 \\
\hline इMUFA & 0.68 & 0.69 & 0.79 & 0.67 & 0.74 & 0.75 & 0.02 & 0.5989 \\
\hline ¿PUFA & 0.79 & 0.77 & 0.75 & 0.78 & 0.72 & 0.86 & 0.02 & 0.5743 \\
\hline इn-6 PUFA & 0.67 & 0.66 & 0.66 & 0.75 & 0.63 & 0.74 & 0.02 & 0.5503 \\
\hline 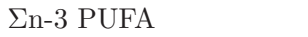 & $0.83^{\mathrm{a}}$ & $0.73^{\mathrm{ab}}$ & $0.79^{\mathrm{a}}$ & $0.56^{\mathrm{b}}$ & $0.78^{\mathrm{ab}}$ & $0.86^{\mathrm{a}}$ & 0.03 & 0.0514 \\
\hline
\end{tabular}

${ }^{\mathrm{a}-\mathrm{c}}$ Means within a row with different superscripts within a fixed factor significantly differ $(P<0.05)$.

${ }^{1} \mathrm{LA}=$ linoleic acid; ALA $=\alpha$-linolenic acid; EPA $=$ eicosapentaenoic acid; DHA $=$ docosahexaenoic acid; DPA $=$ docosapentaenoic acid.

${ }^{2} \mathrm{CO}=$ canola oil; $\mathrm{RBO}=$ rice bran oil; $\mathrm{FSO}=$ flaxseed oil; $\mathrm{SFO}=$ safflower oil; $\mathrm{RPO}=$ rumen-protected oil. 
Table 6. Mean values of main long-chain PUFA in 1 standard serving of cheese $(\mathrm{mg} / 40 \mathrm{~g})$

\begin{tabular}{|c|c|c|c|c|c|c|c|c|}
\hline Fatty acid ${ }^{1}$ & \multicolumn{6}{|c|}{$\operatorname{Diet}^{2}$} & SEM & $P$-value \\
\hline $18: 2 \mathrm{n}-6$ LA & $302.7^{\mathrm{b}}$ & $235.4^{\mathrm{c}}$ & $297.8^{\mathrm{b}}$ & $329.7^{\mathrm{b}}$ & $414.3^{\mathrm{a}}$ & $320.8^{\mathrm{b}}$ & 11.3 & 0.0001 \\
\hline 18:3n-3 ALA & $66.3^{\mathrm{c}}$ & $61.1^{\mathrm{cd}}$ & $54.3^{\mathrm{d}}$ & $113.8^{\mathrm{a}}$ & $61.9^{\mathrm{cd}}$ & $92.0^{\mathrm{b}}$ & 4.0 & 0.0001 \\
\hline 20:5n-3 EPA & $10.6^{\mathrm{b}}$ & $8.2^{\mathrm{c}}$ & $9.2^{\mathrm{bc}}$ & $10.2^{\mathrm{bc}}$ & $9.1^{\mathrm{bc}}$ & $14.3^{\mathrm{a}}$ & 0.5 & 0.0001 \\
\hline 22:6n-3 DHA & $4.9^{\mathrm{b}}$ & $4.4^{\mathrm{b}}$ & $4.7^{\mathrm{b}}$ & $5.2^{\mathrm{b}}$ & $6.1^{\mathrm{b}}$ & $12.8^{\mathrm{a}}$ & 0.6 & 0.0001 \\
\hline 22:5n-3 DPA & $10.7^{\mathrm{b}}$ & $10.0^{\mathrm{b}}$ & $10.3^{\mathrm{b}}$ & $11.8^{\mathrm{b}}$ & $10.5^{\mathrm{b}}$ & $17.1^{\mathrm{a}}$ & 0.6 & 0.0001 \\
\hline
\end{tabular}

${ }^{\mathrm{a}-\mathrm{d}}$ Means within a row with different superscripts within a fixed factor significantly differ $(P<0.05)$.

${ }^{1} \mathrm{LA}=$ linoleic acid; $\mathrm{ALA}=\alpha$-linolenic acid; $\mathrm{EPA}=$ eicosapentaenoic acid; DHA $=$ docosahexaenoic acid; DPA $=$ docosapentaenoic acid.

${ }^{2} \mathrm{CO}=$ canola oil; $\mathrm{RBO}=$ rice bran oil; $\mathrm{FSO}=$ flaxseed oil; $\mathrm{SFO}=$ safflower oil; $\mathrm{RPO}=$ rumen-protected oil.

\section{DISCUSSION}

\section{Effect of Oil Supplementation on the Proportion of Beneficial PUFA in Ripened Cheese}

Cheese produced from FSO milk showed a marked improvement in total n-3 PUFA due to its high ALA proportion compared with all other treatments. Our findings agree with previous results from other studies that also examined the effect of adding flaxseed to dairy sheep (Zhang et al., 2006b; Bodas et al., 2010; Mughetti et al., 2012) and dairy cow (Santillo et al., 2016) diets on the FA profile of cheese. The high level of ALA in the diet supplemented to the ewes accounted for this enrichment. Although ruminal biohydrogenation of ALA for most diets is very high and varies from 85 to $100 \%$ (Glasser et al., 2008b; Shingfield et al., 2010), the postruminal infusion, as in our treatments, increased the passage rate of ALA through the rumen for eventual absorption in the abomasum and subsequent transfer and conversion into milk fat in the mammary gland (Glasser et al., 2008a). Typically, supplementation with oilseeds rich in ALA, such as flaxseed, also has the potential to enhance the concentration of 20:5n-3 (EPA) in milk and the final product through the elongation and desaturation of 18:3n-3 in mammalian tissues (Leonard et al., 2004). Kazama et al. (2010) and Khas et al. (2010) reported a minor but significant increase in EPA content in dairy cows. However, outcomes observed in the current study are in agreement with the results of Cattani et al. (2014) and Bodas et al. (2010), who did not find any significant correlation between ALA in the diet and EPA content in the milk product. Species differences in mammary lipid metabolism could be the principal reason for these disparities (Chilliard et al., 2014).

The greatest improvement of n-3 LC-PUFA was observed in RPO cheese. This outcome was in agreement with several studies that targeted an increase in EPA and DHA contents in ovine milk by supplementing lactating ewes with diets containing high levels of these ingredients (Kitessa et al., 2004; Reynolds et al., 2006; Toral et al., 2010a,b; Bichi et al., 2013). Polyunsaturated FA, EPA, and DHA are also biohydrogenated in the rumen, resulting in the production of 18:0 (Palmquist et al., 2005), but this occurs to a lesser extent than for the biohydrogenation of LA and ALA (Chilliard et al., 2000). Given the relatively low absorption rate from the small intestine into the mammary gland, ranging from 14.3 to $33.0 \%$ for EPA and 13.3 to $25.0 \%$ for DHA (Shingfield et al., 2013), it is not surprising that the proportion of these 2 n-3 LC-PUFA in dairy products

Table 7. Effect of different diets on sensory eating quality of sheep cheese

\begin{tabular}{|c|c|c|c|c|c|c|c|c|}
\hline \multirow[b]{2}{*}{ Item } & \multicolumn{6}{|c|}{$\operatorname{Diet}^{1}$} & \multirow[b]{2}{*}{ SEM } & \multirow[b]{2}{*}{$P$-value } \\
\hline & Control & $\mathrm{CO}$ & FSO & $\mathrm{RBO}$ & $\mathrm{SFO}$ & $\mathrm{RPO}$ & & \\
\hline Appearance & $5.0^{\mathrm{c}}$ & $5.0^{\mathrm{c}}$ & $7.0^{\mathrm{a}}$ & $7.3^{\mathrm{a}}$ & $6.2^{\mathrm{b}}$ & $6.1^{\mathrm{b}}$ & 0.13 & 0.0001 \\
\hline Aroma & $5.9^{\mathrm{ab}}$ & $5.6^{\mathrm{b}}$ & $6.7^{\mathrm{a}}$ & $6.6^{\mathrm{a}}$ & $6.5^{\mathrm{a}}$ & $6.1^{\mathrm{ab}}$ & 0.10 & 0.0097 \\
\hline Flavor & $5.8^{\mathrm{b}}$ & $4.2^{\mathrm{c}}$ & $7.3^{\mathrm{a}}$ & $7.5^{\mathrm{a}}$ & $5.7^{\mathrm{b}}$ & $5.5^{\mathrm{b}}$ & 0.15 & 0.0001 \\
\hline Texture & $5.6^{\mathrm{b}}$ & $5.0^{\mathrm{b}}$ & $7.0^{\mathrm{a}}$ & $7.0^{\mathrm{a}}$ & $5.8^{\mathrm{b}}$ & $5.7^{\mathrm{b}}$ & 0.14 & 0.0001 \\
\hline Overall liking & $5.7^{\mathrm{b}}$ & $4.4^{\mathrm{c}}$ & $7.5^{\mathrm{a}}$ & $7.5^{\mathrm{a}}$ & $6.0^{\mathrm{b}}$ & $5.7^{\mathrm{b}}$ & 0.15 & 0.0001 \\
\hline
\end{tabular}


Table 8. Pearson correlation coefficients ${ }^{1}$ between sensory eating quality traits and selected fatty acids of sheep cheese

\begin{tabular}{|c|c|c|c|c|c|}
\hline Item $^{2}$ & Appearance & Aroma & Flavor & Texture & Overall liking \\
\hline \multicolumn{6}{|l|}{ Appearance } \\
\hline Aroma & $0.52 * * *$ & & & & \\
\hline Flavor & $0.61^{* * *}$ & $0.56^{* * *}$ & & & \\
\hline Texture & $0.57^{* * *}$ & $0.53^{* * *}$ & $0.72^{* * *}$ & & \\
\hline Overall liking & $0.65^{* * *}$ & $0.62^{* * *}$ & $0.91^{* * *}$ & $0.76^{* * *}$ & \\
\hline 18:2 CLA & 0.46 & 0.40 & 0.39 & 0.32 & 0.37 \\
\hline $18: 2 n-6$ LA & 0.40 & 0.59 & 0.22 & 0.20 & 0.28 \\
\hline 18:3n-3 ALA & 0.45 & 0.16 & 0.31 & 0.31 & 0.28 \\
\hline 20:5n-3 EPA & -0.09 & -0.24 & -0.29 & -0.29 & -0.27 \\
\hline 22:6n-3 DHA & 0.01 & -0.08 & -0.23 & -0.22 & -0.19 \\
\hline 22:5n-3 DPA & 0.02 & -0.16 & -0.25 & -0.23 & -0.22 \\
\hline$\Sigma$ SFA & 0.36 & 0.41 & 0.38 & 0.43 & 0.43 \\
\hline इMUFA & -0.68 & -0.76 & -0.58 & -0.61 & -0.64 \\
\hline$\Sigma \mathrm{PUFA}$ & 0.52 & 0.57 & 0.31 & 0.28 & 0.35 \\
\hline ¿n-6 PUFA & 0.39 & 0.59 & 0.22 & 0.21 & 0.28 \\
\hline इn-3 PUFA & 0.37 & 0.09 & 0.18 & 0.18 & 0.16 \\
\hline \multicolumn{6}{|c|}{$\begin{array}{l}{ }^{1} \text { Degree of correlation: } 0.00-0.19=\text { very weak, } 0.20-0.39=\text { weak, } 0.40-0.59=\text { moderate, } 0.60-0.79=\text { stror } \\
0.80-1.0=\text { very strong. }\end{array}$} \\
\hline
\end{tabular}

is generally very low. However, the significant improvement in total n-3 PUFA content at the expense of a significant decrease of 18:0 in the RPO treatment (Table 3 ) indicates that using rumen-protected EPA + DHA in supplementary diets is an effective physiological and biochemical by-pass of rumen biohydrogenation and a smart escape from the negative effect of typical fat metabolism in dairy sheep. This substitution of long-chain SFA with PUFA in human diets has been reported to reduce the risk of coronary heart disease ( $\mathrm{Hu}$ et al., 1999). In addition, because of the resultant elevated total n-3 PUFA, the inclusion of flaxseed oil and rumen-protected EPA + DHA significantly reduced the ratio of n- 6 to n-3 FA (2.65/1 and 2.47/1, respectively). These ratio values are close to the ratio of $2.5 / 1$ that had been reported to have a positive effect in colorectal cancer patients by reducing rectal cell proliferation and between the ratio of 2 to $3 / 1$ that inhibited inflammation in rheumatoid arthritis (Simopoulos, 2002).

Although safflower has been known as one of the richest sources of LA, studies on the influence of supplementing dairy sheep diets with safflower oil on FA compositions have not been found by the authors. The largest improvement of LA, observed in the SFO group, was due to the high proportion of this FA in the diet. This present finding is in line with previously reported results by Bell et al. (2006) and $\mathrm{Li}$ et al. (2015), who evaluated the effect of safflower oil on dairy cows' FA. These outcomes also supported the conclusion of Shingfield et al. (2013) that similar to ALA, the amount of LA during mammary gland secretion strongly depends on the amount of infused FA in the abomasum. The highest ratio of n-6 to n-3 (5.17 vs. 3.72) occurred in SFO cheese over the control, and as a result of LA enhancement, this ratio is still within the optimal n- $6 / \mathrm{n}-3$ ratio of $<6: 1$ (Zymon et al., 2014).

Rice bran is an agricultural by-product known to be an effective energy and FA dietary feed source for livestock due to its high content of oleic, linoleic, and palmitic acids (Warren and Farrell, 1990; Cicero and Derosa, 2005). Canola, on the other hand, has adequate concentrations of n-3 and n-6 PUFA (Sakhno, 2010) and is by far the largest oilseed crop in Australia (Seymour et al., 2012). Despite its availability and accessability, peer-reviewed published information on the use of these plant lipid sources in the Australian dairy sheep industry is limited. The limited ability of supplementing sheep diets with rice bran and canola oils to enhance the availability of desired PUFA in cheese in this study aligned with previous studies in cow milk (Lunsin et al., 2012; Otto et al., 2014) and goat milk (Mir et al., 1999; Park et al., 2013). Adding rice bran oil in the diet for experimental animals increased the concentration of medium-chain SFA 14:0 and 16:0 in cheese, and this agrees with the results of Park et al. (2013), who observed increased proportions of SFA 14:0 and 16:0 in goat milk due to the high proportions of these FA in rice bran oil. The increased proportions of these 2 SFA show the potentially negative effect of the RBO diet on the cheese FA profile of lactating ewes. Subsequently, a high consumption level of 14:0 and 16:0 in humans may increase low-density lipoprotein cholesterol, which 
is associated with atherosclerotic cardiovascular disease (Siri-Tarino et al., 2010).

\section{Effect of Oil Supplementation on the Recovery of LC-PUFA of Ripened Cheese}

To date, there is a paucity of studies assessing FA retention in ripened cheese produced from sheep milk supplemented with oil pellets. Cattani et al. (2014) demonstrated no statistical differences in the recovery of group FA and all individual FA, including LA, ALA, and EPA in ripened cheese processed from milk produced by cows supplemented with 500 or $1,000 \mathrm{~g}$ of extruded flaxseed. Our investigation, however, observed significant differences in the transfer rates for ALA, EPA, and total n-3 PUFA from raw milk to ripened cheese in grazing dairy sheep. This disparity between the 2 studies could be the result of differences in dietary supplements, species, or cheese making processes. Further research is therefore needed to better elucidate the effect of adding oils in dietary supplements for dairy ewes on the recovery of FA in ripened cheese.

\section{Effect of Oil Supplementation on the Absolute Concentration of LC-PUFA and Eating Quality of Ripened Cheese}

In 2016, 260,000 t of cheese was traded in Australia, where the annual cheese consumption was estimated to be $13.5 \mathrm{~kg}$ per person (Dairy Australia, 2016). These values make cheese the second major dairy product after milk for the Australian domestic market. To assist in the promotion of the health and nutritional benefits of dairy products as one of the key focuses of the Australian dairy industry, our research examined the nutritional value of cheese from ewe milk in terms of selected beneficial LC-PUFA per standard serving (mg/40 g; NHMRC, 2013). These absolute data can potentially assist consumers in purchasing decisions. The LA at $414.3 \mathrm{mg} /$ serving in the SFO treatment corresponds to a $137 \%$ increase compared with the control. Adhering to Australian nutritional values, the content of this essential n- 6 FA contributes only a small proportion of approximately 3.2 and $6.2 \%$ of the 13 and 8 $\mathrm{g} / \mathrm{d}$ required for adequate intake in men and women, respectively (NHMRC, 2006). The increase of ALA in FSO cheese was almost double the value observed in the control, accounting for approximately 8.8 and $14.2 \%$ of the adequate intake level requirements for men and women (1.3 and $0.8 \mathrm{~g} / \mathrm{d}$ ), respectively (NHMRC, 2006). In comparison, the ALA content in 1 serving of cheese produced from the FSO treatment was markedly higher than that in a 100-g serving of cooked lamb meat at $48.5 \mathrm{mg} / 100 \mathrm{~g}$, as reported by Flakemore et al. (2017).
Previous studies on n-3 LC-PUFA often have generally focused on EPA and DHA rather than also including DPA, although DPA consumption also contributes to reduced risk of heart disease (Rissanen et al., 2000; Phang et al., 2009; Chen et al., 2012) and the inhibition of inflammation (Chen et al., 2012). This shortcoming may in part be due to pure DPA not being produced at commercial levels; consequently, its effects in both animal models and ultimately human consumers remain very much understudied. In line with suggested dietary targets by NHMRC (2006), this study has also included EPA, DHA, and DPA in the total n-3 LCPUFA. In 1 serving of RPO cheese, the content of total n-3 LC-PUFA at $44.3 \mathrm{mg}$ accounts for 28 and $49 \%$ of the daily dietary target of 90 and $160 \mathrm{mg} / \mathrm{d}$ required for men and women, respectively. The minimum recommended daily intake of milk and alternative products of 2.5 servings per day (NHMRC, 2013) corresponds to $100 \mathrm{~g}$ of cheese/d in adults; at this serving size, RPO cheese can provide up to $69 \%$ of the total n-3 LC-PUFA requirement for men and exceeds the requirement for women, as depicted in Figure 1. Moreover, at an excess of $30 \mathrm{mg} /$ serving, RPO cheese can be considered as meeting the "source" (30 mg/serving) level of n-3 LCPUFA based on FSANZ (2002) guidelines.

Besides nutritional value, appearance, aroma, flavor, and texture are very important features of commercial cheese marketing that affect consumer choice (Awad et al., 2007). The enhancement of all sensory eating traits observed in the RBO and FSO groups were inconsistent with previous studies that showed a minor effect on cheese sensory attributes made with milk from sheep (Nájera et al., 2017) or cows (Ryhanen et al., 2005; Vargas-Bello-Pérez et al., 2015) supplemented different

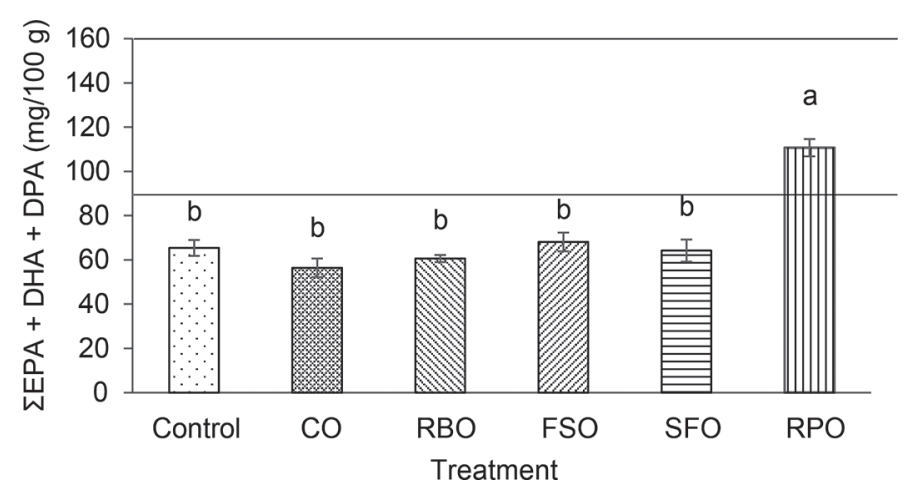

Figure 1. Mean values of total eicosapentaenoic acid (EPA) + docosahexaenoic acid (DHA) + docosapentaenoic acid (DPA; mg/100 g) in cheese. Different letters (a,b) indicate significant differences between treatments $(P<0.05)$. $\mathrm{CO}=$ canola oil; $\mathrm{RBO}=$ rice bran oil; $\mathrm{FSO}=$ flaxseed oil; $\mathrm{SFO}=$ safflower oil; $\mathrm{RPO}=$ rumen-protected oil. Lines indicate the daily required intake of n-3 long-chain PUFA for women $(90 \mathrm{mg} / \mathrm{d})$ and men $(160 \mathrm{mg} / \mathrm{d})$. Error bars indicate SE. 
plant oils. In the current study, no statistical correlation between FA content and sensory attributes was observed, although levels of MUFA showed a strongly negative effect on cheese eating quality. In addition, cheese flavor is due to contributions from complex agents, including mainly milk constituents such as casein, milk fat, lactose, and citrate (Singh et al., 2003) combined with the activity of microorganisms during the ripening period (Pastorino et al., 2003; Sheehan and Guinee, 2004; Awad et al., 2007). This current study primarily focused on improving the FA profile of ripened cheese. Further research, therefore, is recommended to investigate the effect of utilizing milk from ewes supplemented with flaxseed and rice bran oils on cheese manufacture focusing on microbiological, biochemical, and chemical aspects of cheese ripening.

\section{CONCLUSIONS}

Outcomes of this novel on-farm study demonstrated a valuable process of increasing the healthy food functionality and consumer acceptability of sheep cheese fortified with dietary n-3 LC-PUFA. Feeding rumen bypass-protected EPA + DHA to grazing dairy sheep offers the best strategy to increase desired n-3 LCPUFA in cheese without any negative effect on eating quality. Inclusion of flaxseed oil elevates not only the concentration of ALA but also all sensory attributes significantly. The diet containing safflower oil was the most effective in relation to LA enhancement, with a minor improvement in customer sensory evaluation results. Diets including rice bran and canola oil demonstrated minor effects on cheese PUFA, and rice bran oil had a positive effect on cheese eating quality in this study. Due to the current paucity of data and knowledge in the published literature, further research should be performed regarding the optimum level of rice bran and canola oil supplementation in grazing dairy sheep to further elevate the proportion of valuable cheese FA. In addition, precise interactions between cheese processing and oil supplementation also need to be examined to maximize transferred rate of healthy FA from sheep milk into ripened cheese.

\section{ACKNOWLEDGMENTS}

This study was supported by the Australian Awards PhD Scholarship offered to the first-named author at James Cook University (Queensland, Australia) by the Department of Foreign Affairs and Trade of the Australian Government. We acknowledge CopRice Feeds (Cobden, Victoria, Australia) for producing the experimental pellets to specification. We thank John
Otto, Aaron Flakemore (University of Tasmania), and Patti Virtue (CSIRO Hobart), who provided assistance in the field and laboratory with fatty acid analyses and laboratory equipment maintenance. We are also grateful to Diane Rae, Nicole Gilliver, and Ryan Hartshorn (Grandvewe Cheeses Farm, Birchs Bay, Woodbridge, Tasmania, Australia) for providing ready access to experimental animals, milking, cheese processing, and other facilities for this research project.

\section{REFERENCES}

AOAC. 1999. Official Methods of Analysis. AOAC International, Gaithersburg, MD.

Awad, S., N. Ahmed, and M. El Soda. 2007. Evaluation of isolated starter lactic acid bacteria in Ras cheese ripening and flavour development. Food Chem. 104:1192-1199.

Bell, J. A., J. M. Griinari, and J. J. Kennelly. 2006. Effect of safflower oil, flaxseed oil, monensin, and vitamin $\mathrm{E}$ on concentration of conjugated linoleic acid in bovine milk fat. J. Dairy Sci. 89:733-748.

Bichi, E., G. Hervas, P. G. Toral, J. J. Loor, and P. Frutos. 2013. Milk fat depression induced by dietary marine algae in dairy ewes: Persistency of milk fatty acid composition and animal performance responses. J. Dairy Sci. 96:524-532.

Bisig, W., P. Eberhard, M. Collomb, and B. Rehberger. 2007. Influence of processing on the fatty acid composition and the content of conjugated linoleic acid in organic and conventional dairy products-A review. Lait 87:1-19.

Bodas, R., T. Manso, A. R. Mantecon, M. Juarez, M. A. De la Fuente, and P. Gomez-Cortes. 2010. Comparison of the fatty acid profiles in cheeses from ewes fed diets supplemented with different plant oils. J. Agric. Food Chem. 58:10493-10502.

Buccioni, A., S. Minieri, G. Conte, D. Benvenuti, A. Pezzati, M. Antongiovanni, S. Rapaccini, and M. Mele. 2012. Changes in conjugated linoleic acid and C18:1 isomers profile during the ripening of Pecorino Toscano cheese produced with raw milk. Ital. J. Anim. Sci. 11:426-430.

Castro, T., T. Manso, V. Jimeno, M. Del Alamo, and A. R. Mantecon. 2009. Effects of dietary sources of vegetable fats on performance of dairy ewes and conjugated linoleic acid (CLA) in milk. Small Rumin. Res. 84:47-53.

Cattani, M., R. Mantovani, S. Schiavon, G. Bittante, and L. Bailoni. 2014. Recovery of n-3 polyunsaturated fatty acids and conjugated linoleic acids in ripened cheese obtained from milk of cows fed different levels of extruded flaxseed. J. Dairy Sci. 97:123-135.

Chen, J., Y. Jiang, Y. T. Liang, X. Y. Tian, C. Peng, K. Y. Ma, J. Liu, Y. Huang, and Z. Y. Chen. 2012. DPA n-3, DPA n-6 and DHA improve lipoprotein profiles and aortic function in hamsters fed a high cholesterol diet. Atherosclerosis 221:397-404.

Chilliard, Y., A. Ferlay, R. M. Mansbridge, and M. Doreau. 2000. Ruminant milk fat plasticity: Nutritional control of saturated, polyunsaturated, trans and conjugated fatty acids. Ann. Zootech. 49:181-205.

Chilliard, Y., F. Glasser, A. Ferlay, L. Bernard, J. Rouel, and M. Doreau. 2007. Diet, rumen biohydrogenation and nutritional quality of cow and goat milk fat. Eur. J. Lipid Sci. Technol. 109:828855.

Chilliard, Y., P. G. Toral, K. J. Shingfield, J. Rouel, C. Leroux, and L. Bernard. 2014. Effects of diet and physiological factors on milk fat synthesis, milk fat composition and lipolysis in the goat: A short review. Small Rumin. Res. 122:31-37.

Cicero, A. F. G., and G. Derosa. 2005. Rice bran and its main components: Potential role in the management of coronary risk factor. Curr. Top. Nutraceutical Res. 3:29-46.

Collomb, M., A. Schmid, R. Sieber, D. Wechsler, and E. L. Ryhanen. 2006. Conjugated linoleic acids in milk fat: Variation and physiological effects. Int. Dairy J. 16:1347-1361. 
Dairy Australia. 2016. Australian dairy industry in focus 2016. Accessed Mar. 24, 2018. https://www.dairyaustralia.com.au/ publications/australian-dairy-industry-in-focus-2016?id= 4801EB12663D4FDF93150963BE85B614.

Flakemore, A. R., B. S. Malau-Aduli, P. D. Nichols, and A. E. MalauAduli. 2017. Omega-3 fatty acids, nutrient retention values, and sensory meat eating quality in cooked and raw Australian lamb. Meat Sci. 123:79-87.

FSANZ (Food Standards Australia New Zealand). 2002. Standard 1.2.8: Nutrition information requirements. Australia New Zealand Food Standards Code. Vol. 2. FSANZ, Canberra, Australia.

Fuentes, L., J. Mateo, E. J. Quinto, and I. Caro. 2015. Changes in quality of nonaged pasta filata Mexican cheese during refrigerated vacuum storage. J. Dairy Sci. 98:2833-2842.

Glasser, F., A. Ferlay, M. Doreau, P. Schmidely, D. Sauvant, and Y. Chilliard. 2008a. Long-chain fatty acid metabolism in dairy cows: A meta-analysis of milk fatty acid yield in relation to duodenal flows and de novo synthesis. J. Dairy Sci. 91:2771-2785.

Glasser, F., R. Schmidely, D. Sauvant, and M. Doreau. 2008b. Digestion of fatty acids in ruminants: A meta-analysis of flows and variation factors: 2. C18 fatty acids. Animal 2:691-704.

Gomez-Cortes, P., P. G. Toral, P. Frutos, M. Juarez, M. A. de la Fuente, and G. Hervas. 2011. Effect of the supplementation of dairy sheep diet with incremental amounts of sunflower oil on animal performance and milk fatty acid profile. Food Chem. 125:644651 .

Hu, F. B., M. J. Stampfer, J. E. Manson, A. Ascherio, G. A. Colditz, F. E. Speizer, C. H. Hennekens, and W. C. Willett. 1999. Dietary saturated fats and their food sources in relation to the risk of coronary heart disease in women. Am. J. Clin. Nutr. 70:1001-1008.

Kazama, R., C. Cortes, D. da Silva-Kazama, N. Gagnon, C. Benchaar, L. M. Zeoula, G. T. D. Santos, and H. V. Petit. 2010. Abomasal or ruminal administration of flax oil and hulls on milk production, digestibility, and milk fatty acid profile of dairy cows. J. Dairy Sci. 93:4781-4790.

Khas-Erdene, Q., J. Q. Wang, D. P. Bu, L. Wang, J. K. Drackley, Q. S. Liu, G. Yang, H. Y. Wei, and L. Y. Zhou. 2010. Short communication: Responses to increasing amounts of free alpha-linolenic acid infused into the duodenum of lactating dairy cows. J. Dairy Sci. 93:1677-1684.

Kitessa, S. M., S. K. Gulati, G. C. Simos, J. R. Ashes, T. W. Scott, E. Fleck, and P. C. Wynn. 2004. Supplementation of grazing dairy cows with rumen-protected tuna oil enriches milk fat with n-3 fatty acids without affecting milk production or sensory characteristics. Br. J. Nutr. 91:271-278.

Leonard, A. E., S. L. Pereira, H. Sprecher, and Y.-S. Huang. 2004. Elongation of long-chain fatty acids. Prog. Lipid Res. 43:36-54.

Li, R., F. Beaudoin, A. A. Ammah, N. Bissonnette, C. Benchaar, X. Zhao, C. Z. Lei, and E. M. Ibeagha-Awemu. 2015. Deep sequencing shows microRNA involvement in bovine mammary gland adaptation to diets supplemented with linseed oil or safflower oil. BMC Genomics 16:884-889.

Lim, J. Y. 2011. Hedonic scaling: A review of methods and theory. Food Qual. Prefer. 22:733-747.

Lunsin, R., M. Wanapat, C. Yuangklang, and P. Rowlinson. 2012. Effect of rice bran oil supplementation on rumen fermentation, milk yield and milk composition in lactating dairy cows. Livest. Sci. 145:167-173.

Malau-Aduli, A. E. O., B. W. B. Holman, A. Kashani, and P. D. Nichols. 2016. Sire breed and sex effects on the fatty acid composition and content of heart, kidney, liver, adipose and muscle tissues of purebred and first-cross prime lambs. Anim. Prod. Sci. $56: 2122-2132$.

Mendis, S., and O. Chestnov. 2014. Global Status Report on Noncommunicable Diseases 2014. World Health Organization, Geneva, Switzerland.

Mir, Z., L. A. Goonewardene, E. Okine, S. Jaegar, and H. D. Scheer. 1999. Effect of feeding canola oil on constituents, conjugated linoleic acid (CLA) and long chain fatty acids in goats milk. Small Rumin. Res. 33:137-143.
Mughetti, L., F. Sinesio, G. Acuti, C. Antonini, E. Moneta, M. Peparaio, and M. Trabalza-Marinucci. 2012. Integration of extruded linseed into dairy sheep diets: Effects on milk composition and quality and sensorial properties of Pecorino cheese. Anim. Feed Sci. Technol. 178:27-39.

Nájera, A. I., M. A. Bustamante, M. Albisu, I. Valdivielso, G. Amores, N. Mandaluniz, J. Arranz, L. J. R. Barron, and M. de Renobales. 2017. Fatty acids, vitamins and cholesterol content, and sensory properties of cheese made with milk from sheep fed rapeseed oilcake. J. Dairy Sci. 100:6962-6971.

NHMRC (National Health and Medical Research Council). 2006. Nutrient Reference Values for Australia and New Zealand Including Recommended Dietary Intakes. Commonwealth Department of Health and Ageing, Canbera, Australia.

NHMRC (National Health and Medical Research Council). 2013. Australian Dietary Guidelines Educator Guide. National Health and Medical Research Council, Canbera, Australia.

Nudda, A., G. Battacone, O. B. Neto, A. Cannas, A. H. D. Francesconi, A. S. Atzori, and G. Pulina. 2014. Feeding strategies to design the fatty acid profile of sheep milk and cheese. Brazil. J. Anim. Sci. 43:445-456.

OECD/FAO (Organisation for Economic Cooperation and Development). 2011. OECD-FAO Agriculture Outlook 2011-2020. OECD/FAO. Accessed Mar. 25, 2018. https://www.who.int/nmh/ publications/ncd-status-report-2014/en/.

Otto, J. R., B. S. Malau-Aduli, P. D. Nichols, and A. E. O. MalauAduli. 2014. Influence of supplementing pasture-based primiparous Holstein-Friesian dairy cows with crude degummed canola oil on milk fatty acid composition. J. Nutr. Ther. 3:55-66.

Palmquist, D. L., A. L. Lock, K. J. Shingfield, and D. E. Bauman. 2005. Biosynthesis of conjugated linoleic acid in ruminants and humans. Adv. Food Nutr. Res. 50:179-217.

Park, J. K., E. G. Kwon, and C. H. Kim. 2013. Effects of increasing supplementation levels of rice bran on milk production and fatty acid composition of milk in Saanen dairy goats. Anim. Prod. Sci. $53: 413-418$

Pastorino, A. J., C. L. Hansen, and D. J. McMahon. 2003. Effect of pH on the chemical composition and structure-function relationships of cheddar cheese. J. Dairy Sci. 86:2751-2760.

Phang, M., M. L. Garg, and A. J. Sinclair. 2009. Inhibition of platelet aggregation by omega-3 polyunsaturated fatty acids is gender specific-Redefining platelet response to fish oils. Prostaglandins Leukot. Essent. Fatty Acids 81:35-40.

Prandini, A., S. Sigolo, and G. Piva. 2011. A comparative study of fatty acid composition and CLA concentration in commercial cheeses. J. Food Compos. Anal. 24:55-61.

Reynolds, C. K., V. L. Cannon, and S. C. Loerch. 2006. Effects of forage source and supplementation with soybean and marine algal oil on milk fatty acid composition of ewes. Anim. Feed Sci. Technol. 131:333-357.

Rissanen, T., S. Voutilainen, K. Nyyssonen, T. A. Lakka, and J. T. Salonen. 2000. Fish oil-derived fatty acids, docosahexaenoic acid and docosapentaenoic acid, and the risk of acute coronary eventsThe Kuopio ischaemic heart disease risk factor study. Circulation 102:2677-2679.

Ryhanen, E. L., K. Tallavaara, J. M. Griinari, S. Jaakkola, S. MantereAlhonen, and K. J. Shingfield. 2005. Production of conjugated linoleic acid enriched milk and dairy products from cows receiving grass silage supplemented with a cereal-based concentrate containing rapeseed oil. Int. Dairy J. 15:207-217.

Sakhno, L. O. 2010. Variability in the fatty acid composition of rapeseed oil: Classical breeding and biotechnology. Cytol. Genet. 44:389-397.

Santillo, A., M. Caroprese, R. Marino, F. d'Angelo, A. Sevi, and M. Albenzio. 2016. Fatty acid profile of milk and Cacioricotta cheese from Italian Simmental cows as affected by dietary flaxseed supplementation. J. Dairy Sci. 99:2545-2551.

Seymour, M., J. A. Kirkegaard, M. B. Peoples, P. F. White, and R. J. French. 2012. Break-crop benefits to wheat in Western Australia-Insights from over three decades of research. Crop Pasture Sci. 63:1-16. 
Sheehan, J. J., and T. P. Guinee. 2004. Effect of pH and calcium level on the biochemical, textural and functional properties of reducedfat Mozzarella cheese. Int. Dairy J. 14:161-172.

Shingfield, K. J., L. Bernard, C. Leroux, and Y. Chilliard. 2010. Role of trans fatty acids in the nutritional regulation of mammary lipogenesis in ruminants. Animal 4:1140-1166.

Shingfield, K. J., M. Bonnet, and N. D. Scollan. 2013. Recent developments in altering the fatty acid composition of ruminant-derived foods. Animal 7:132-162.

Simopoulos, A. P. 2002. The importance of the ratio of omega-6/ omega-3 essential fatty acids. Biomed. Pharmacother. 56:365-379.

Singh, T. K., M. A. Drake, and K. R. Cadwallader. 2003. Flavor of cheddar cheese: A chemical and sensory perspective. Compr. Rev. Food Sci. Food Saf. 2:166-189.

Siri-Tarino, P. W., Q. Sun, F. B. Hu, and R. M. Krauss. 2010. Saturated fatty acids and risk of coronary heart disease: Modulation by replacement nutrients. Curr. Atheroscler. Rep. 12:384-390.

Toral, P. G., P. Frutos, G. Hervas, P. Gomez-Cortes, M. Juarez, and M. A. de la Fuente. 2010a. Changes in milk fatty acid profile and animal performance in response to fish oil supplementation, alone or in combination with sunflower oil, in dairy ewes. J. Dairy Sci. 93:1604-1615.

Toral, P. G., G. Hervas, P. Gomez-Cortes, P. Frutos, M. Juarez, and M. A. de la Fuente. 2010b. Milk fatty acid profile and dairy sheep performance in response to diet supplementation with sunflower oil plus incremental levels of marine algae. J. Dairy Sci. 93:1655-1667.

Vargas-Bello-Pérez, E., K. Fehrmann-Cartes, G. Iniguez-Gonzalez, P. Toro-Mujica, and P. C. Garnsworthy. 2015. Short communication: Chemical composition, fatty acid composition, and sensory characteristics of Chanco cheese from dairy cows supplemented with soybean and hydrogenated vegetable oils. J. Dairy Sci. 98:111-117.

Warren, B. E., and D. J. Farrell. 1990. The nutritive value of full-fat and defatted Australian rice bran. I. Chemical composition. Anim. Feed Sci. Technol. 27:219-228.

Zhang, R., A. F. Mustafa, and X. Zhao. 2006a. Effects of flaxseed supplementation to lactating ewes on milk composition, cheese yield, and fatty acid composition of milk and cheese. Small Rumin. Res. 63:233-241.

Zhang, R. H., A. F. Mustafa, and X. Zhao. 2006b. Effects of feeding oilseeds rich in linoleic and linolenic fatty acids to lactating ewes on cheese yield and on fatty acid composition of milk and cheese. Anim. Feed Sci. Technol. 127:220-233.

Zymon, M., J. Strzetelski, and G. Skrzynski. 2014. Aspects of appropriate feeding of cows for production of milk enriched in the fatty acids, EPA and DHA. A review. J. Anim. Feed Sci. 23:109-116. 